Het er ogeneous react i on $r$ at e const ant s by st eady- st at e mi croel ect rode techni ques and fast scan vol tammet $r y$

\begin{tabular}{|l|l|}
\hline 著者 & $\begin{array}{l}\text { Aoki Kochi Jer emiah, Zhang Chaof u, Chen } \\
\text { Ji ngyuan, N shi um Toyohi ko }\end{array}$ \\
\hline $\begin{array}{l}\text { j our nal or } \\
\text { publ i cat i on ti t l e }\end{array}$ & Journal of El ect r oanal yt i cal Chem st ry \\
\hline vol une & 706 \\
\hline page range & $40-47$ \\
\hline year & $2013-05$ \\
\hline URL & ht t p: //hdl . handl e. net /10098/8128 \\
\hline
\end{tabular}




\title{
Heterogeneous reaction rate constants by steady-state microelectrode techniques and fast scan voltammetry
}

\author{
Kochi Jeremiah Aoki ${ }^{1}$, Chaofu Zhang, Jingyuan Chen, Toyohiko Nishiumi \\ Department of Applied Physics, University of Fukui, \\ 3-9-1 Bunkyo, Fukui-shi, 9108507 Japan
}

\begin{abstract}
Rate constants of fast electron transfer reactions of hexachloroiridium, hexaammine ruthenium, aminoferrocene, tetracyanoquinodimethan (TCNQ), ferrocenecarboxylic acid and ferrocene, which have been determined equivocally by fast voltammetry, are attempted to be evaluated with steady-state voltammetric measurements at ultramicroelectrodes. This work is motivated by the experimental feasibility of high current density at ultramicroelectrodes without effects of capacitive currents or solution resistance. The theory of mass transport mentions that current densities by steady-state voltammetry at electrodes $10 \mu \mathrm{m}$ and $1 \mu \mathrm{m}$ in diameter correspond, respectively, to 2.1 $\mathrm{V} \mathrm{s}^{-1}$ and $210 \mathrm{~V} \mathrm{~s}^{-1}$ scan rates at large electrodes. However, no potential shift is observed even at electrodes $0.01 \mu \mathrm{m}$ in diameter for the six species. This fact implies that the heterogeneous rate constants are at least larger than $10 \mathrm{~cm} \mathrm{~s}^{-1}$. Fast scan voltammetry is carried out at a large electrode for scan rates less than $10 \mathrm{~V} \mathrm{~s}^{-1}$. Peak-to-peak potentials increase with an increase in the scan rates. This variation is fitted to the mass transport equation complicated by the electrode kinetics for the rate constant of $0.01-0.1 \mathrm{~cm} \mathrm{~s}^{-1}$. The inconsistency between the two methods is ascribed partly to solution resistance and partly to the resistance relevant to the electric double layer at fast scan voltammetry. The contribution of the solution resistance is demonstrated from the facts that the peak currents vary linearly with the peak potentials, that the slope of the linearity is independent of kinds of redox species, and that the slope corresponding to the conductivity has a linear relationship with concentration of supporting electrolyte.
\end{abstract}

\footnotetext{
${ }^{1}$ corresponding author: kaoki@u-fukui.ac.jp (K.J. Aoki)
} 
key words: steady-state microelectrode techniques; fast voltammetry; heterogeneous rate constants; diffusion-controlled current

\section{Introduction}

An advantage of the voltammetric behavior at a microelectrode is to exhibit a steady-state current-voltage curve when the current is controlled by diffusion of electroactive species [1-3]. It is due to the existence of a mathematical solution for the 3D-diffusional Laplace equation [4]. The diffusion-controlled limiting current, $I_{\mathrm{L}}$, for the one-electron exchange reaction at the inlaid disk electrode $a$ in radius is expressed by [5]

$$
I_{\mathrm{L}}=4 F c^{*} D a
$$

where $c^{*}$ is the concentration of a redox species, and $D$ is its diffusion coefficient. The average current density, $j_{\mathrm{L}}=(4 / \pi) F c^{*} D / a$, is enhanced with a decrease in the electrode diameter. On the other hand, the voltammetric current density at a large electrode is enhanced with an increase in scan rates, $v$. When the expression for the current density at the microelectrode is set equal to the equation for the peak current density by linear sweep voltammetry $\left(j_{\mathrm{p}}=0.446 F c^{*}(D v F / R T)^{1 / 2}\right)$, the relation between the scan rate and the radius is expressed by

$v=8.15 R T D / F a^{2}$

Typical values of $v$ for $a=10 \mu \mathrm{m}, 100 \mathrm{~nm}$ and $1 \mathrm{~nm}$ are, respectively, $2.1 \mathrm{~V} \mathrm{~s}^{-1}, 21 \mathrm{kV}$ $\mathrm{s}^{-1}, 210 \mathrm{MV} \mathrm{s}^{-1}$ for $D=10^{-5} \mathrm{~cm}^{2} \mathrm{~s}^{-1}$ at $25^{\circ} \mathrm{C}$. Therefore the steady-state voltammetry at nano-electrodes allows us to obtain such fast electron transfer kinetic data as not to be realized by the conventional fast scan voltammetry. However, it is dangerous to consider simply Eq. (2) from the diffusion process, because the heterogeneous reaction occurs at electrode surfaces rather than in the diffusion layer. This question will be discussed in this report. 
The correspondence (Eq. (2)) has not yet been confirmed by experimental data on the rate constants. Electron transfer rate constants of ferrocenyl compounds determined at nano-electrodes have varied from researchers to researchers [6-10]. They are sometimes consistent or sometimes inconsistent with those by fast scan voltammetry [8-16], short pulse methods [17], ac impedance methods [11,18-20] and hydrodynamic voltammetry [21]. The other techniques are scanning electrochemical microscope by varying distance between two electrodes [10,22-25]. Environments of reactions haven been attempted to be changed into polymer electrolytes [26-28] and low temperature [29]. The wide variation of the rate constants by microelectrode techniques is ascribed to unstable or irreproducible current-potential curves and inaccurate analysis of evaluating the constant. As for the analysis, there are two methods of evaluating the rates constants. One is to obtain the difference between a halfwave potential at a microelectrode and that at a small electrode [14,30-36]. The other is to use a slope of current-potential curve or to simulate the current-potential waveform which is deviated from the Nernstian curve [22,37-41]. In either case, a microelectrode provides only one steady-state current in a given solution, in contrast to fast scan voltammetry by varying scan rates in a wide domain. If a current-potential curve deviates accidentally from the Nernstian curve by adsorption or capacitive currents, the reversible reaction would be judged wrongly as irreversible one. This is a disadvantage of microelectrode techniques in comparison with easy variations of scan rates at a large electrode. In order to determine a rate constant unequivocally, it is necessary to obtain many current-potential curves at different sizes of microelectrodes [41], just as measurements of peak potentials at various scan rates. A key lies in easy fabrication of various sizes of microelectrodes.

Although some fabrication techniques have already been reported and surveyed $[42,43]$, inherent problems have not yet been solved, such as low success rate of the fabrication, poor reproducibility, fragility, temperature- and moisture-dependence, 
degradation of reversibility, and a short life [44]. A long life has been attained by coating the electrode tips with glass $[6,45-50]$ rather than with polymer films. This technique results from such properties of glass as thermal expansion coefficient, rigidity, low degree of swelling, and chemical proof. Our successful fabrication technique is to polish a glass-coated thin platinum wire by monitoring ac-current between an electrode tip and a counter electrode $[32,33]$.

This report deals with comparison of steady-state voltammograms at various sized microelectrodes with fast scan voltammograms at a large electrode for the six redox species of which rate constants are reported to be quasi-reversible. Fast scan voltammetry for quasi-reversible redox species shows potential shifts with an increase in scan rates, whereas microelectrode techniques provide very small or no potential shift $[32,37-41]$. The experimental data reported so far do not support the correspondence between $a$ and $v$ in Eq. (2). Our aim is to point out the contradiction in heterogeneous rate constants obtained by steady-state voltammetry and fast scan voltammetry. We describe firstly a kinetic correspondence between radii of microelectrodes and scan rates of fast voltammetry, secondly report experimental results by the both methods, and finally mention some problems included in fast scan voltammetry.

\section{Experimental}

\subsection{Fabrication of microelectrodes}

Microdisk electrodes with various diameters were fabricated by the previous method $[32,33]$, which was composed of etching of a platinum wire, sealing it with a glass capillary by heat, dissolving the coating glass with hydrofluoric acid, and polishing the glass tip with a monitor of ac-impedance. The exposed platinum surface was observed with a video-microscope, VH-Z450 (Keyence, Osaka) and /or scanning electron microscope, JSM-6701F (JEOL, Tokyo). 


\subsection{Chemicals}

All the chemicals were of analytical grade. Aqueous ammonia, $\mathrm{KOH}, \mathrm{HNO}_{3}$ and $\mathrm{NaNO}_{2}$ were purchased from Nakarai, and the others were from Wako. Ferrocenylmethyltrimethylammonium perchlorate (FcTMA) was synthesized and purified [51]. The experimenters treated hydrofluoric acid in a draft with a tail gas scrubber, wearing gas masks and latex gloves.

\subsection{Voltammetry}

Voltammetry was made in the three-electrode cell equipped with a working electrode and a platinum coil counter electrode. Reference electrodes were a $\mathrm{Ag} \mid \mathrm{AgCl}$ (3 mol dm $\left.\mathrm{dm}^{-3} \mathrm{NaCl}\right)$ for aqueous solutions and $\mathrm{Ag} \mid \mathrm{Ag}^{+}\left(\left[\mathrm{AgNO}_{3}\right]=0.01 \mathrm{M}\right.$ ) for acetonitrile solutions. The potentiostat was HECS 972 (Huso, Kawasaki), controlled with a homemade software. The electrode was rinsed with solvent before mounted in the cell. Voltammetry was carried out in deaerated solution in a Faraday cage.

The normal sized disk platinum electrode, $1.6 \mathrm{~mm}$ in diameter, was used for fast scan voltammetry. The electrode surface was polished on a buff with alumina powder and was rinsed with water before each voltammetric run.

\section{Results and Discussion}

3.1. Theoretical comparison between microelectrode voltammograms and fast scan voltammograms

We here discuss a kinetic relationship between microelectrode voltammetry and fast scan voltammetry at a large electrode. The variables relevant to kinetic current-potential curves are the radius, $a$, of the microdisk electrode, potential scan rates, 
$v$, the standard electron transfer rate constant, $k^{\circ}$, and the anodic transfer coefficient, $\alpha$, in the Butler-Volmer kinetic equation. The current-potential curve at the microdisk electrode has been given approximately by [31,52]

$$
I / I_{\mathrm{L}}=\left(1+\mathrm{e}^{-\varsigma}\right)^{-1} \lambda /(1.38+\lambda)
$$

where

$$
\begin{aligned}
& \lambda=\left(k^{\circ} a / D\right) \mathrm{e}^{\alpha \varsigma}\left(1+\mathrm{e}^{-\varsigma}\right) \\
& \varsigma=\left(E-E^{\circ}\right) F / R T
\end{aligned}
$$

The dimensionless kinetic variable is $k^{\circ} a / D$. In contrast, linear sweep voltammograms were calculated numerically by solving the integral equation by Matsuda [53] with the dimensionless kinetic variable, $k^{0}\left(R T / D v F^{3}\right)^{1 / 2}$. We calculated voltammograms from Eq. (3) for three values of $k^{\circ} a / D$ and from the integral equation for $k^{0}\left(R T / D v F^{3}\right)^{1 / 2}$, where $v$ was replaced by $8.15 R T D / \mathrm{Fa}^{2}$ through Eq. (2). Figure 1 shows voltammograms normalized by $I_{\mathrm{L}}$ or the reversible peak current, $I_{\mathrm{p}, \text { rev }}$. The voltammograms are shifted to the positive potential with a decrease in values of $k^{\circ}$, associated with the broadening.

Characteristics of voltammograms are the halfwave potential, $E_{\mathrm{h}}$, for the steady-state wave and the peak potential, $E_{\mathrm{p}}$, for the fast scan voltammogram. The amount of the shift of $E_{\mathrm{h}}$ is close to that of $E_{\mathrm{p}}$. with the decrease in $k^{\circ}$. For sufficiently small values of $k^{0}$ or for the totally irreversible reaction, we obtain for $E_{\mathrm{h}}$ [51]

$$
E_{\mathrm{h}}=E^{\circ}+(R T / \alpha F) \ln \left(1.38 D / k^{\circ} a\right)
$$

In contrast, $E_{\mathrm{p}}$ for the totally irreversible case is expressed by [53]

$$
E_{\mathrm{p}}=E^{\circ}+(R T / \alpha F) \ln \left(\frac{2.18}{k^{\circ}} \sqrt{\frac{\alpha F v D}{R T}}\right)
$$

Taking equal in both equations, we obtain the kinetic correspondence between $v$ and $a$ : $v=0.4 R T D / \alpha F a^{2}$

This is smaller by $20 \alpha$ times smaller than Eq. (3). In other word, the effect of the scan rate on the heterogeneous kinetics appears more sensitively (by ca. 10 times) than that 
on the diffusion-controlled current. Then the kinetic correspondences of $v$ at $a=10 \mu \mathrm{m}$, $100 \mathrm{~nm}$ and $1 \mathrm{~nm}$ are, respectively, $0.21 \mathrm{~V} \mathrm{~s}^{-1}, 2.1 \mathrm{kV} \mathrm{s}^{-1}, 21 \mathrm{MV} \mathrm{s}^{-1}$ for $D=10^{-5} \mathrm{~cm}^{2} \mathrm{~s}^{-1}$ at $25^{\circ} \mathrm{C}$.

In order to see clearly the difference between $E_{\mathrm{h}}$ and $E_{\mathrm{p}}$, we evaluated $E_{\mathrm{h}}$ and $E_{\mathrm{p}}$ for various values of $k^{0} a / D$ and $k^{0}\left(R T / D v F^{3}\right)^{1 / 2}$, changing $k^{0}$ at $\alpha=0.5$ when $a$ was replaced by $v$ through Eq. (2). Plot of $E_{\mathrm{p}}$ against $E_{\mathrm{h}}$ falls on a line for $E_{\mathrm{h}}-E^{0}>0.05 \mathrm{~V}$, as shown in Fig. 2. The slope of the line is unity. When values of $k^{\circ} a / D$ increase, the plot in the quasi-reversible potential domain, $E_{\mathrm{h}}-E^{0}<0.05 \mathrm{~V}$, varies complicatedly to reach $E_{\mathrm{h}}=$ $E^{\mathrm{o}}$ and $E_{\mathrm{p}}=59 \mathrm{mV}+E^{\mathrm{o}}$.

Behavior at microdisk electrodes is often analyzed approximately with that a microhemispherical electrode. We compare kinetic correspondence between the microdisk electrode and a hemispherical electrode. Diffusion controlled limiting current at the hemispherical electrode $a_{\mathrm{hs}}$ in radius is given by $I_{\mathrm{L}, \mathrm{hs}}=2 \pi F c^{*} D a_{\mathrm{hs}}$. Equating it to Eq. (1) yields $a_{\mathrm{hs}}=0.64 a$. On the other hand, the halfwave potential under the heterogeneous kinetic control at the hemispherical electrode is given by [51]

$$
E_{\mathrm{h}, \mathrm{hs}}=E^{\circ}+(R T / \alpha F) \ln \left(D / k^{\circ} a_{\mathrm{hs}}\right)
$$

Comparison of Eq. (7) with Eq. (4) yields $a_{\mathrm{hs}}=0.72 a$. It is close to the diffusion-controlled value.

We use the method of evaluating the rate constants from the dependence of halfwave potentials on the electrode radii. The other possible method is to use the slope of the steady-state current-potential curve at the half-wave potential $[24,38,41]$. Since the current-potential curve at a disk electrode is almost the same as that at a hemispherical electrode, we obtain the expression for the slope at hemispherical electrode. From Eq. (11) in reference 31, the inverse slope for $\alpha=0.5$ is expressed by

$$
E_{\text {slope }}=\left(\frac{\mathrm{d} E}{\mathrm{~d}\left(I / I_{\mathrm{L}}\right)}\right)_{E_{1 / 2}}=\frac{8 R T}{F} \frac{\sqrt{1+4\left(k^{\circ} a / D\right)^{2}}+1+2\left(k^{\circ} a / D\right)^{2}}{\sqrt{1+4\left(k^{\circ} a / D\right)^{2}}+1+4\left(k^{\circ} a / D\right)^{2}}
$$


The value of $E_{\text {slope }}$ for the Nernstian response is $4 R T / F=102.6 \mathrm{mV}$ at $25^{\circ} \mathrm{C}$. We plotted variations of $E_{\text {slope }}$ against $E_{\mathrm{h}}$ in Fig. 3, where the halfwave potential is related with $k^{\circ} a / D$ through $D / k^{\circ} a=2 \sinh \left[\left(F\left(E_{\mathrm{h}}-E^{o}\right) / 2 R T\right]\right.$. The tangent line of $E_{\text {slope }}$ at $E_{\mathrm{h}}=E^{\circ}$ is

$$
E_{\text {slope }}=4 R T / F+2\left(E_{\mathrm{h}}-E^{\circ}\right)
$$

Since variation of $E_{\text {slope }}$ with $k^{0}$ is twice that of $E_{\mathrm{h}}$, evaluation of $k^{0}$ from $E_{\text {slope }}$ seems to be more sensitive than from $E_{\mathrm{h}}$. However, values of $E_{\text {slope }}$ may include errors larger than those of $E_{\mathrm{h}}$, because not only of differential values of the current-potential curves but also of large influence of irreproducible capacitive currents.

\subsection{Experimental fast scan and steady state voltammograms}

We confirmed that voltammograms were independent of durations of polishing electrode surfaces and immersion of electrodes into acid. The radii of the electrodes were evaluated from the limiting currents of FcTMA in aqueous solutions and ferrocene in acetonitrile solutions through Eq. (1), where the value of the diffusion coefficients of FcTMA and ferrocene were $0.63 \times 10^{-5} \mathrm{~cm}^{2} \mathrm{~s}^{-1}$ and $1.55 \times 10^{-5} \mathrm{~cm}^{2} \mathrm{~s}^{-1}$, respectively [51]. Values of the radii thus determined represent the ones averaged through spherical diffusion even if an electrode is deformed from a disk or has a rough surface. The limiting current at an elliptic surface has been demonstrated to be the same as that obtained at the disk electrode of which area is the same as the ellipse [54]. The geometrical radii estimated by SEM were larger than those by the limiting current when the diameters were less than $5 \mu \mathrm{m}[33,55]$. However, the difference will be insignificant in the conclusion of this report.

We selected tetracyanoquinodimethan (TCNQ), ferrocenecarboxylic acid, hexaammineruthenium chloride, and hexachlorideiridium as electroactive species with 
fast charge transfer reaction rate constants. Voltammetry of the first two was made in acetonitrile, whereas that of the latter two was in water. Steady-state currents with pico-ampere have been observed without extremely meticulous techniques, partly because a huge number of current values are averaged and partly because capacitive currents are suppressed. This advantage is, however, liable to be disturbed by deterioration of electrode surfaces by adsorption owing to long time measurements. In order to estimate a degree of blocking of the current, we used ferrocene in acetonitrile solutions and FcTMA in aqueous solutions as probes of monitoring diffusion-controlled currents and halfwave potentials [51]. Some microelectrodes showed hysteretic voltammograms ascribed to the charging current. When the charging current, which was obtained in the blank solution, was subtracted from the voltammograms, the current at the forward scan current was mostly overlapped with that at the backward one.

Voltammograms of $\mathrm{Ru}\left(\mathrm{NH}_{3}\right)_{6}{ }^{3+}$

Figure 4(A) shows voltammograms of the $\mathrm{Ru}\left(\mathrm{NH}_{3}\right)_{6}{ }^{3+}+$ FcTMA aqueous solution at microelectrodes with several diameters. The wave with the halfwave potentials at $-0.17 \mathrm{~V}$ is caused by the reduction of $\mathrm{Ru}\left(\mathrm{NH}_{3}\right)_{6}{ }^{3+}$, while that at $0.41 \mathrm{~V}$ is by the oxidation of FcTMA. The waves except (not shown) at the largest electrode $(2 a=0.1$ $\mathrm{mm}$ ) were sufficiently under the steady state, i.e., the current at the forward scan overlapping with that at the backward scan. Several iterative scans did not alter the voltammograms. The ratio of the limiting current of $\mathrm{Ru}\left(\mathrm{NH}_{3}\right)_{6}{ }^{3+}$ to that of FcTMA was plotted against the calculated radii of the electrodes in Fig. 5 (filled triangles). It is independent of the radii, indicating that the current was not blocked with adsorbed layers caused by high current density [51]. The ratio 0.90 was close to the concentration ratio, 0.89 .

Figure 4(B) shows fast scan voltammograms at the large electrode $(1.6 \mathrm{~mm}$ in 
diameter). The voltammetric peaks correspond to the steady-state waves in Fig. 4(A). The peak potentials of both $\mathrm{Ru}\left(\mathrm{NH}_{3}\right)_{6}{ }^{3+}$ and FcTMA did not vary with the scan rates. The peak currents, $I_{\mathrm{p}}$, were approximately proportional to the square-roots of the scan rates, but were slightly larger than the proportional line at high scan rates for both $\mathrm{Ru}\left(\mathrm{NH}_{3}\right)_{6}{ }^{3+}$ and FcTMA, as is shown in Fig. 6(e) and (f). The enhancement may not be ascribed to the Faradaic currents but may be caused by the electric double layer capacitance, as will be discussed in Section 3.3.

Voltammograms of $\mathrm{IrCl}_{6}^{-2}$

Figure 7(A) shows voltammograms in aqueous solutions of $\mathrm{IrCl}_{6}{ }^{2-}$ and FcTMA, both of which were observed in different cells. The reduction currents are of $\mathrm{IrCl}_{6}{ }^{2-}$ and the oxidation ones are of FcTMA. A microelectrode used for $\mathrm{IrCl}_{6}{ }^{2-}$ voltammetry was rinsed and then soon was employed for FcTMA voltammetry. Therefore the voltammograms in Fig. 7 can be regarded as the waves hypothetically obtained in mixed solution of $\mathrm{IrCl}_{6}{ }^{2-}$ and FcTMA. When the two species were mixed, the spontaneous reaction, $\mathrm{IrCl}_{6}{ }^{2-}+\mathrm{FcTMA} \rightarrow \mathrm{IrCl}_{6}{ }^{3-}+\mathrm{FcTMA}^{+}$, occurred. The voltammogram of the mixture exhibited two waves, but were broader than as predicted. Thus, the mixing products should contain other species than $\mathrm{IrCl}_{6}{ }^{3-}+\mathrm{FcTMA}^{+}$. Figure 5 (squares) shows the plot of the ratio, $\left|I_{\mathrm{Ir}}\right| / I_{\mathrm{FcTMA}}$, against the radii which were evaluated from the limiting currents of FcTMA. The invariance to the radii suggests no complication by adsorption.

Figure 7(B) shows fast scan voltammograms of $\mathrm{IrCl}_{6}{ }^{3-}$ at the large electrode. The peak potentials were shifted slightly with the scan rates. The peak currents deviated upward from the proportionality line of $I_{\mathrm{p}}$ vs. $v^{1 / 2}$ plot (in Fig. $6(\mathrm{~d})$ ), as is similar to $\mathrm{Ru}\left(\mathrm{NH}_{3}\right)_{6}{ }^{3+}$ and FcTMA. 
Voltammograms of TCNQ

Figure $8(\mathrm{~A})$ shows voltammograms of TCNQ + ferrocene in the acetonitrile solution. The wave with a halfwave potential at $0.10 \mathrm{~V}$ is due to oxidation of ferrocene. TCNQ showed two reduction waves at $-0.10 \mathrm{~V}$ and $-0.66 \mathrm{~V}$ for the formation of anion and the dianion radicals, respectively. The steady state was established enough for iterative scans. The limiting current of the second anodic wave was twice that of the first one. The ratios of the first limiting currents and the difference of the second current from the first one to that of ferrocene were plotted against the radii of the electrode in Fig. 5 (circles). They were independent of the radii. Therefore no adsorption layer was formed at high current density.

Figure $8(\mathrm{~B})$ shows fast scan voltammograms of TCNQ + ferrocene. Three peaks correspond clearly to the three steady-state voltammograms in Fig. 8(A). The peak potential differences for the three reactions increased with an increase in the scan rates. The potential shift may suggest contribution of heterogeneous kinetics and/or solution resistance. The contribution should generally make the plot of $I_{\mathrm{p}}$ vs. $v^{1 / 2}$ deviate lower from the proportionality at high scan rates, associated with the peak potential shift. However, the $I_{\mathrm{p}}$ vs. $v^{1 / 2}$ plot in Fig. 6(c) exhibits the well-defined proportionality. The inconsistency between the potential shift and the proportionality will be explained in terms of capacitive currents by potential scans in Section 3.3.

\section{Voltammograms of ferrocenecarboxile acid}

Figure 9(A) shows voltammograms of ferrocenecarboxylic acid (FcA) and ferrocene in acetonitrile. Since the both species are in the reduced form, the voltammograms are composed of a sum of the oxidation wave of ferrocene at $0.10 \mathrm{~V}$ and that of $\mathrm{FcA}$ at 0.31 V. They were stable for iterative scans. The ratio of the current of FcA to that of 
ferrocene did not vary with the radii, as shown in Fig. 5 (open triangles). Consequently there is no complication by adsorption.

Fast scan voltammograms of FcA (Fig 9(B)) show two oxidation peaks, as predicted. The peak potential shifted with an increase in the scan rates so that the corresponding peaks were separated. The $I_{\mathrm{p}}$ vs. $v^{1 / 2}$ plot exhibited well-defined proportionality, as is shown in Fig. 6(a).

\subsection{Analysis}

The halfwave potentials of the steady-state waves of the six species are plotted against $\log (a)$ in Fig. 10. Here, points of $E_{\mathrm{h}}$ for FcTMA, the second wave of TCNQ, and FcA were displaced by given values so that the they lay within the scale of the graph. The halfwave potentials for each species were invariant to the radii. Therefore no kinetic effect of the heterogeneous reactions can be recognized for the six species. The theoretical variation of the halfwave potential for the oxidation at $\alpha=0.5$ can be obtained by setting $I / I_{\mathrm{L}}$ to be $1 / 2$ in Eq. (3), i.e.

$$
0.5=\left(k^{\circ} a / D\right)\left(\mathrm{e}^{\zeta_{\mathrm{h}} / 2}+\mathrm{e}^{-\zeta_{\mathrm{h}} / 2}\right)\left(1+\mathrm{e}^{-\zeta_{\mathrm{h}}}\right)^{-1} /\left(1.38+\left(k^{\circ} a / D\right)\left(\mathrm{e}^{\zeta_{\mathrm{h}} / 2}+\mathrm{e}^{-\zeta_{\mathrm{h}} / 2}\right)\right)
$$

or

$$
\frac{k^{\circ} a}{D}=\frac{1.38}{\exp \left(\zeta_{\mathrm{h}} / 2\right)-\exp \left(-\zeta_{\mathrm{h}} / 2\right)}
$$

Variations of the halfwave potential with $\log (a)$ are drawn in Fig. 10 for $k^{0}=0.01,0.1$, 1.0 , and $10.0 \mathrm{~cm} \mathrm{~s}^{-1}, D=10^{-5} \mathrm{~cm}^{2} \mathrm{~s}^{-1}$ and $E^{\mathrm{o}}=-0.10 \mathrm{~V}$. With a decrease in the radius, the halfwave potential is shifted in the positive direction gradually, and increases linearly with $\log (a)$. This variation cannot be found in the experimental data even for $2 a$ $=4 \mathrm{~nm}$. The experimental variations are flatter than curve (d) for $k^{0}=10 \mathrm{~cm} \mathrm{~s}^{-1}$. Therefore the six species should have $k^{0}$ values larger than $10 \mathrm{~cm} \mathrm{~s}^{-1}$. This estimation 
agrees with Amemiya's result [24], but is not consistent with the values of $k^{\circ}$ determined by the other researchers in fast scan voltammetry [8-13]. It is not consistent with our data of fast scan voltammetry, either, in that the peak potentials shifted with an increase in $v$.

Here we analyze the peak potentials in detail. Figure 11 shows plot of the anodic and the cathodic peak potentials against $\log (v)$ for ferrocene and the first and the second wave of TCNQ. The difference in $E_{\mathrm{p}}$ of the pair peaks at $v=0.1 \mathrm{~V} \mathrm{~s}^{-1}$ was ca. $70 \mathrm{mV}$, being common to the three pairs. The difference increased with an increase in the scan rates. A potential shift caused by the totally irreversible reaction should be $\pm 2.3 R T / \alpha F$, according to Eq. (5), which is displayed as two lines (a) in Fig. 11 for $\alpha=0.5$. Since the experimental values show slopes smaller than $2.3 R T / \alpha F$, three reactions may belong to the quasi-reversible kinetics. We attempted to fit the variations in Fig. 11 by numerically solving the integral equation [53] for various values of $k^{0}$. The simulated plots are shown for the first wave of TCNQ as two solid curves in Fig. 11 for $k^{0}=0.017$ $\mathrm{cm} \mathrm{s}^{-1}$ at $\alpha=0.5$. Good agreement was obtained. If two largest points in the figure are removed for curve fitting, the $k^{0}$ value is close to $0.1 \mathrm{~cm} \mathrm{~s}^{-1}$. Consequently, the agreement includes ambiguity. Unfortunately, the apparent agreement is inconsistent largely with $k^{\circ}>10 \mathrm{~cm} \mathrm{~s}^{-1}$ which was estimated from the variations of the halfwave potentials vs. radii in Fig. 10.

The inconsistency can be seen through the graph in Fig. 2. The results by the fast scan voltammetry showed $E_{\mathrm{p}}-E^{\circ}=70-80 \mathrm{mV}$, which corresponds to $E_{\mathrm{h}}-E^{\circ}=20-25 \mathrm{mV}$ from Fig. 2. However, the steady-state voltammetry exhibited $E_{\mathrm{h}}-E^{\mathrm{o}}<10 \mathrm{mM}$. The peak potential shift by fast scan voltammetry may be complicated with other effects than the heterogeneous kinetics.

A possible reason of the shift is solution resistance. The solution resistance was evaluated by the technique of linear plot $I_{\mathrm{p}}$ vs. $E_{\mathrm{p}}$ in voltammograms, which has been developed in viscous solutions [56,57]. Figure 12 shows plots of the anodic and the 
cathodic peaks of (A) TCNQ + ferrocene in the acetonitrile solution and $(\mathrm{B}) \mathrm{Ru}\left(\mathrm{NH}_{3}\right)_{6}{ }^{3+}$ + FcTMA in the aqueous solution. The plots fell on each line, suggesting a contribution of solution resistance. Table 1 lists values of the resistance. The potential differences, $E_{\mathrm{p} \text {,anode }}-E_{\mathrm{p} \text {,cathode, }}$ at which $\left|I_{\mathrm{p}}\right|$ was extrapolated to zero ranged from 58 to $62 \mathrm{mV}$ for TCNQ, Fe, FcA, whereas those of FcTMA, $\mathrm{Ru}\left(\mathrm{NH}_{3}\right)_{6}{ }^{3+}$ and $\mathrm{IrCl}_{6}{ }^{2-}$ ranged from 65 to 75 $\mathrm{mV}$. The potential differences are close to the diffusion-controlled value. If the linearity is caused by solution resistance, the slope should represent conductance of the solution. The anodic and the cathodic slopes for TCNQ, ferrocene and FcA were common in acetonitrile solutions, while those for FcTMA $\mathrm{Ru}\left(\mathrm{NH}_{3}\right)_{6}{ }^{3+}$ and $\mathrm{IrCl}_{6}{ }^{2-}$ had another common value in the aqueous solutions. The slope is expected to reveal properties of solvent rather than redox species.

Ionic conductance should be proportional to concentration of salt. Figure 13 shows the plot of the conductance, $G$, (slopes in Fig. 12) against concentrations of $\mathrm{TBAPF}_{6}$ obtained for ferrocene, TCNQ and FcA. The linearity of the plot confirms that the slopes in Fig. 12 should represent the conductance. Since the slope in Fig. 12(B) of the aqueous solutions $(0.2 \mathrm{M} \mathrm{KCl})$ was six times larger than that in Fig. 12(A) of the acetonitrile solutions $\left(0.2 \mathrm{M} \mathrm{TBAPF}_{6}\right)$, the ratio of the conductance may be six. In order to confirm the contribution of the conductance, we carried out ac-impedance for solutions and determined the solution resistances by extrapolating the in-phase component of the Nyquist plot into infinite frequency. The resistance of $0.2 \mathrm{M} \mathrm{KCl}$ by the ac-impedance was $120 \Omega$, whereas that of $0.2 \mathrm{M} \mathrm{TBAPF}_{6}$ was $180 \Omega$ in a common cell at a common electrode. The ratio (1.3) by the impedance is much smaller than the ratio (6.0) in Fig. 12. The resistance for $0.2 \mathrm{M} \mathrm{TBAPF}_{6}$ is read from Fig. 13 to be $300 \Omega$, which is smaller than $180 \Omega$. Therefore, the slopes include other resistances. A possible resistance is a resistance parallel to the electric double layer, which has been necessarily observed when voltage applied to double layers is varied with time [58]. The resistance parallel to the double layer capacitance is an apparent resistance caused by a 
frequency-dependent capacitance. The ac current flowing from the charge $q$ in the capacitance is given by the time-derivative of $q$, i.e. $I=\mathrm{d} q / \mathrm{d} t=\mathrm{d}(C V) / \mathrm{d} t=C(\mathrm{~d} V / \mathrm{d} t)+$ $V(\mathrm{~d} C / \mathrm{d} t)$ when ac-voltage $V=V_{0} \exp (i \omega t)$ is applied to the capacitance, where $V_{0}$ is the ac-amplitude and $\omega$ is the angular velocity. The first term on the right hand side belongs to an out-of phase, Vi $\omega C$, and hence it is a conventional capacitance. In contrast, the second term belongs to an in-phase because the capacitance is a function of the time or the angular velocity. Then the current can be represented as $I=V[i \omega C+(\mathrm{d} C / \mathrm{d} t)]$, which expresses a series combination of the suceptance and the conductance. This means that the equivalent circuit is composed of the parallel combination of the capacitance, $C$, and the resistance, $1 /(\mathrm{d} C / \mathrm{d} t)$. Therefore the peak potential shift at fast scan voltammetry can be ascribed to the unexpected resistances rather than the heterogeneous kinetics.

It is interesting to estimate the rate constants from $E_{\text {slope, }}$ as some researchers did [24,38,41]. Figure 14 shows dependence of $E_{\text {slope }}$ for FcTMA (circles) and ferrocene (triangle) on $\log (a)$, exhibiting no variation. The theoretical variations (Eq. (8)) for $k^{0}=$ $1,0.3$ and $0.1 \mathrm{~cm} \mathrm{~s}^{-1}$ with $\log (a)$ are also drawn in Fig. 14. They increase exponentially with a decrease in $\log (a)$, whereas the experimental values were $E_{\text {slope }}(\mathrm{FcTMA})=109 \pm$ $3 \mathrm{mV}$ and $E_{\text {slope }}($ ferrocene $)=108 \pm 0.3 \mathrm{mV}$, where the errors mean the standard deviations. Therefore the slopes do not show properties of the electrode kinetics. Features of the variations common to the six redox species are

(i) invariance of $E_{\text {slope }}$ to $\log (a)$

(ii) $E_{\text {slope }}$ larger than the value $(102.6 \mathrm{mV})$ of the Nernst response

All the experimental results are inconsistent with the theoretical prediction. Therefore the slope is not a suitable use for evaluating the charge transfer kinetics, but behaves as if there were a kind of resistance of $E_{\text {slope }}-102.6 \mathrm{mM}$. The large scatter is not simply due to individual properties of the electrodes.

\section{Conclusions}


The charge transfer reaction rate constants of ferrocene, TCNQ, FcA, FcTMA, ferrocene, $\mathrm{Ru}\left(\mathrm{NH}_{3}\right)_{6}{ }^{3+}$ and $\mathrm{IrCl}_{6}{ }^{2-}$ are larger than $10 \mathrm{~cm} \mathrm{~s}^{-1}$, according to the invariance of halfwave potentials of the steady-state voltammograms to radii of the microelectrodes. Slopes of the current-potential curves contain so large errors that the rate constants cannot be evaluated. In other word, they are not evaluated unequivocally. This conclusion is inconsistent with results reported so far by fast scan voltammetry, ac impedance techniques and pulse methods. Fast scan voltammetry does not provide unequivocal rate constants, either, because it causes peak potential shift not only by solution resistance but also by the resistance relevant to electric double layers.

\section{Acknowledgement}

This work was financially supported by Grants-in-Aid for Scientific Research (Grants 22550072) from the Ministry of Education in Japan. 


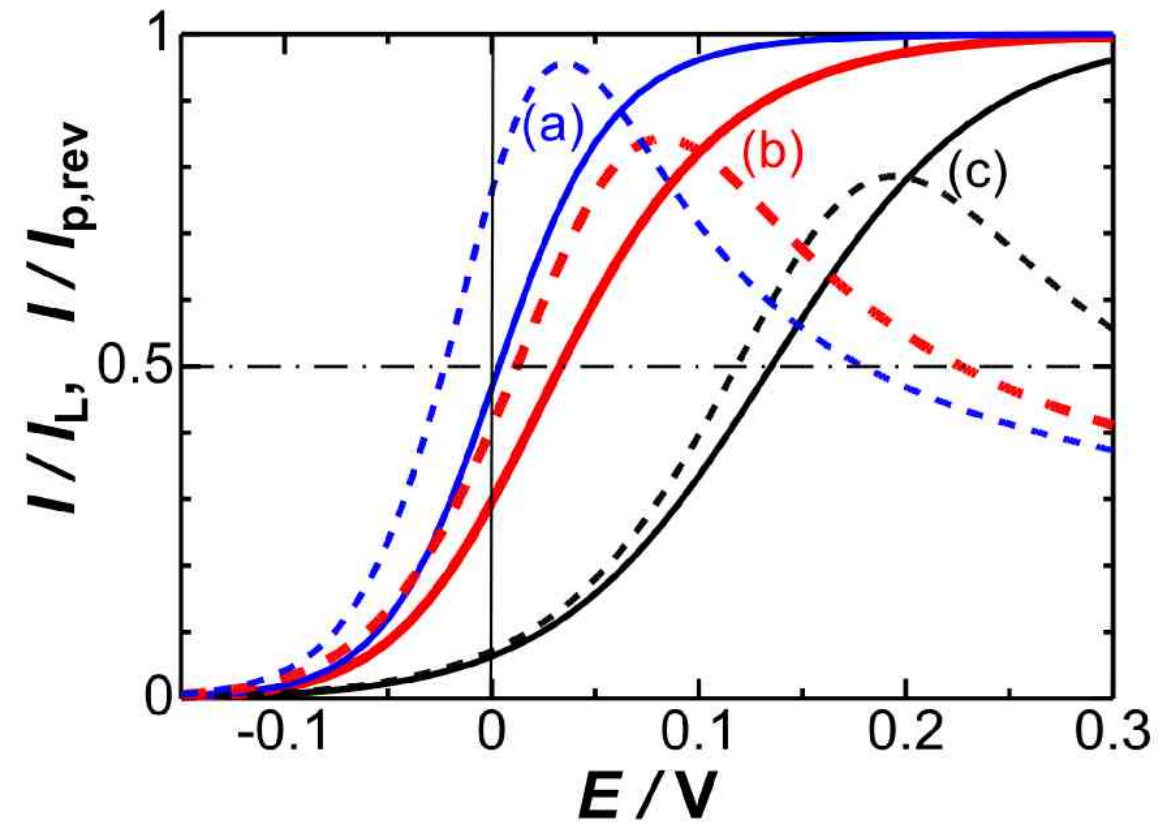

Figure 1. Theoretical linear sweep voltammograms at a microelectrode under the steady state (solid) and at a large electrode by fast scans (dashed curves) for $\alpha=0.5$ and $k^{\circ} a / D$ $=k^{0}(8.15 R T / F D v)^{1 / 2}=$ (a) 10 , (b) 1.0 and (c) 0.1 .

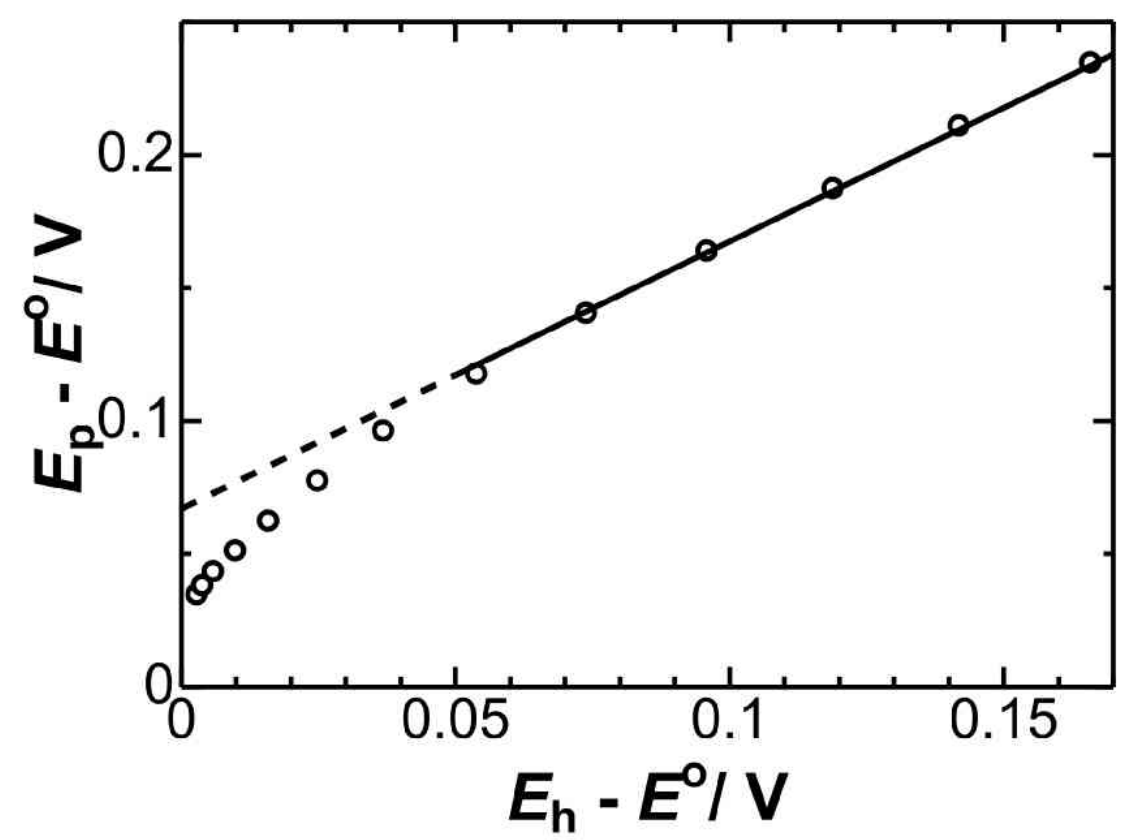

Figure 2. Calculated relationship between the halfwave potential, $E_{\mathrm{h}}$, of the steady-state voltammogram at a microelectrode and the peak potential, $E_{\mathrm{p}}$, of fast scan voltammetry at a large electrode for $\alpha=0.5$. 


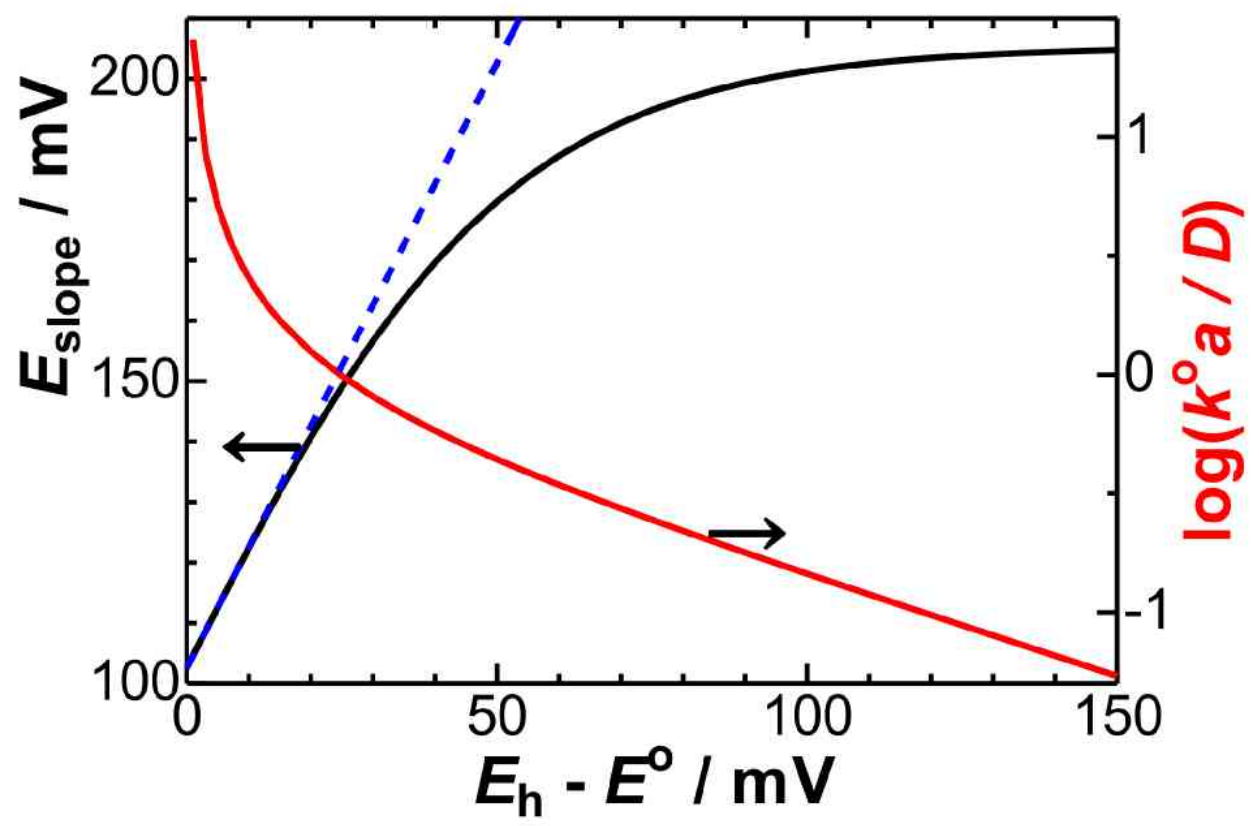

Figure 3. Variation of $E_{\text {slope }}$ with the halfwave potential, calculated from Eq. (8). The relation between $k^{\circ} a / D$ with the halfwave potential is given on the right axis. The dashed line is for Eq. (9). 

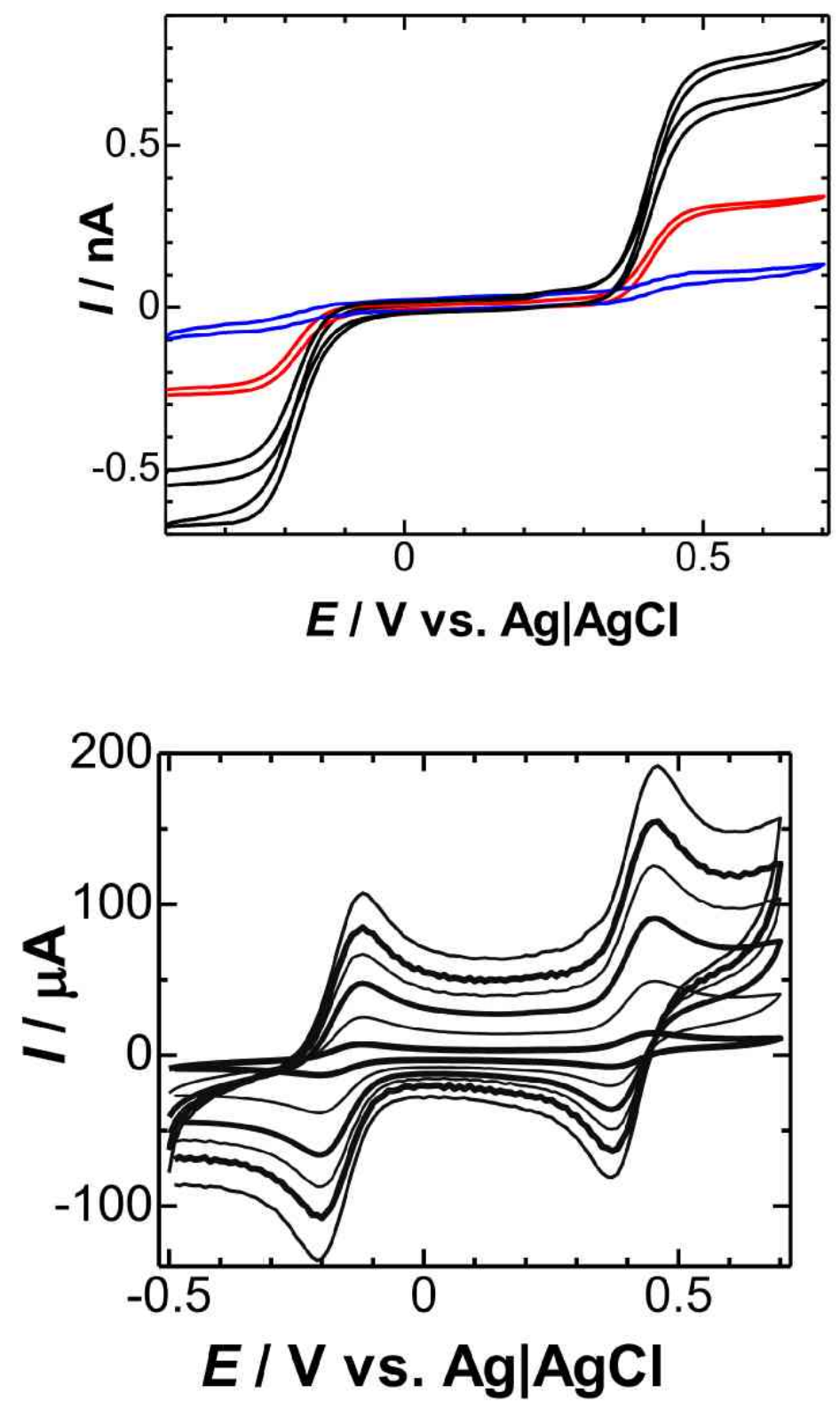

Figure 4. Voltammograms of $1.25 \mathrm{mM} \mathrm{Ru}\left(\mathrm{NH}_{3}\right)_{6}{ }^{3+}+1.4 \mathrm{mM}$ FcTMA in $0.5 \mathrm{M} \mathrm{KNO}_{3}$ aqueous solution (A) at microelectrodes with $a=0.012,0.85,1.7$ and $2.1 \mu \mathrm{m}$ for $v=10$ $\mathrm{mV} \mathrm{s}^{-1}$ and (B) at the large electrode for $v=0.1,1,3,5,7,10 \mathrm{~V} \mathrm{~s}^{-}$ 


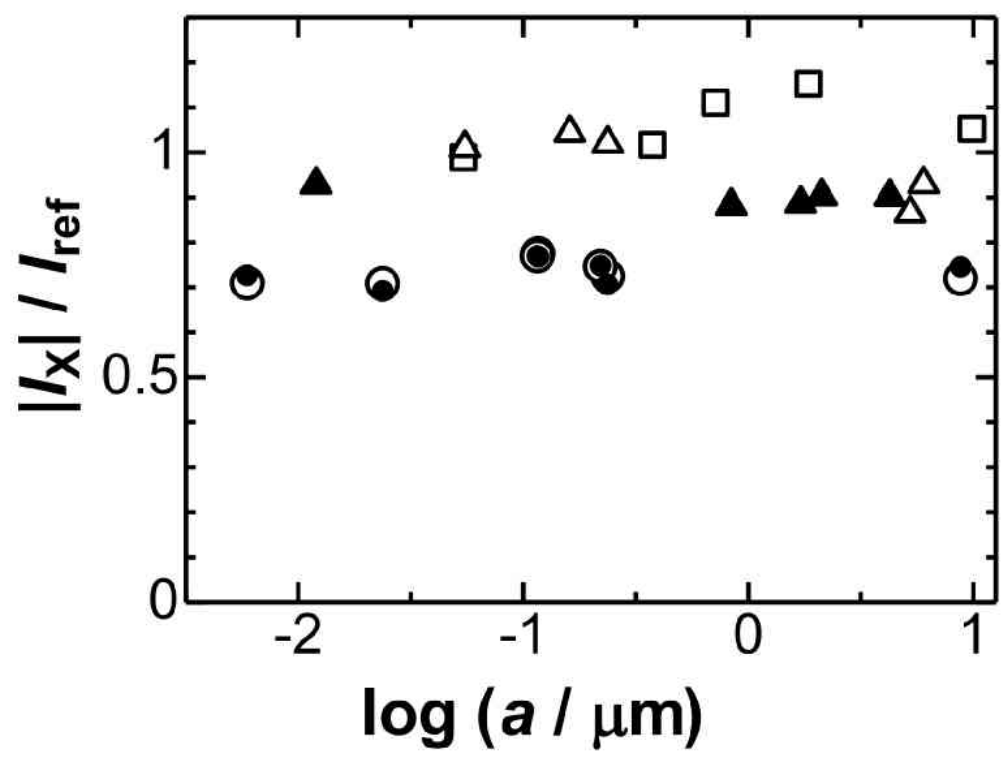

Figure 5. Dependence of the ratios of the limiting current of species $X$ to that of reference species (ferrocene or FcTMA), $I_{\mathrm{X}} / I_{\text {ref }}$, on the radii of microelectrodes, where the radii were evaluated from $I_{\mathrm{Fc}}$ or $I_{\mathrm{FcTMA}}$ through Eq. (1). "X"s are (filled triangles) $\mathrm{Ru}\left(\mathrm{NH}_{3}\right)^{3+}$, (squares) $\mathrm{IrCl}_{6}{ }^{2-}$, (open circles) the first wave of TCNQ, (filled circles) the second wave of TCNQ, and (open triangles) FcA.

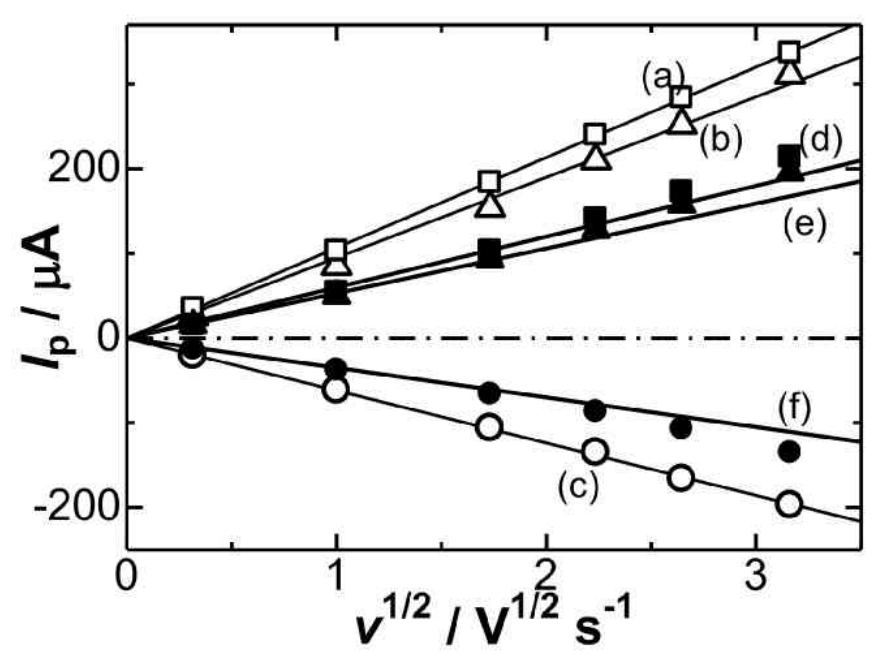

Figure 6. Plot of the peak currents at the large electrode against $v^{1 / 2}$ for (a) FcA, (b)

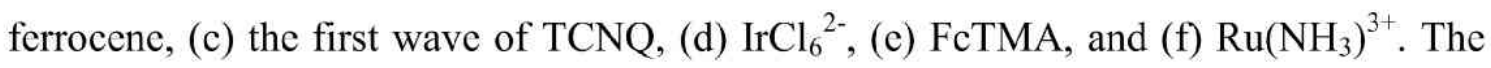
first three were obtained in acetonitrile, whereas the last three were in aqueous 
solutions.
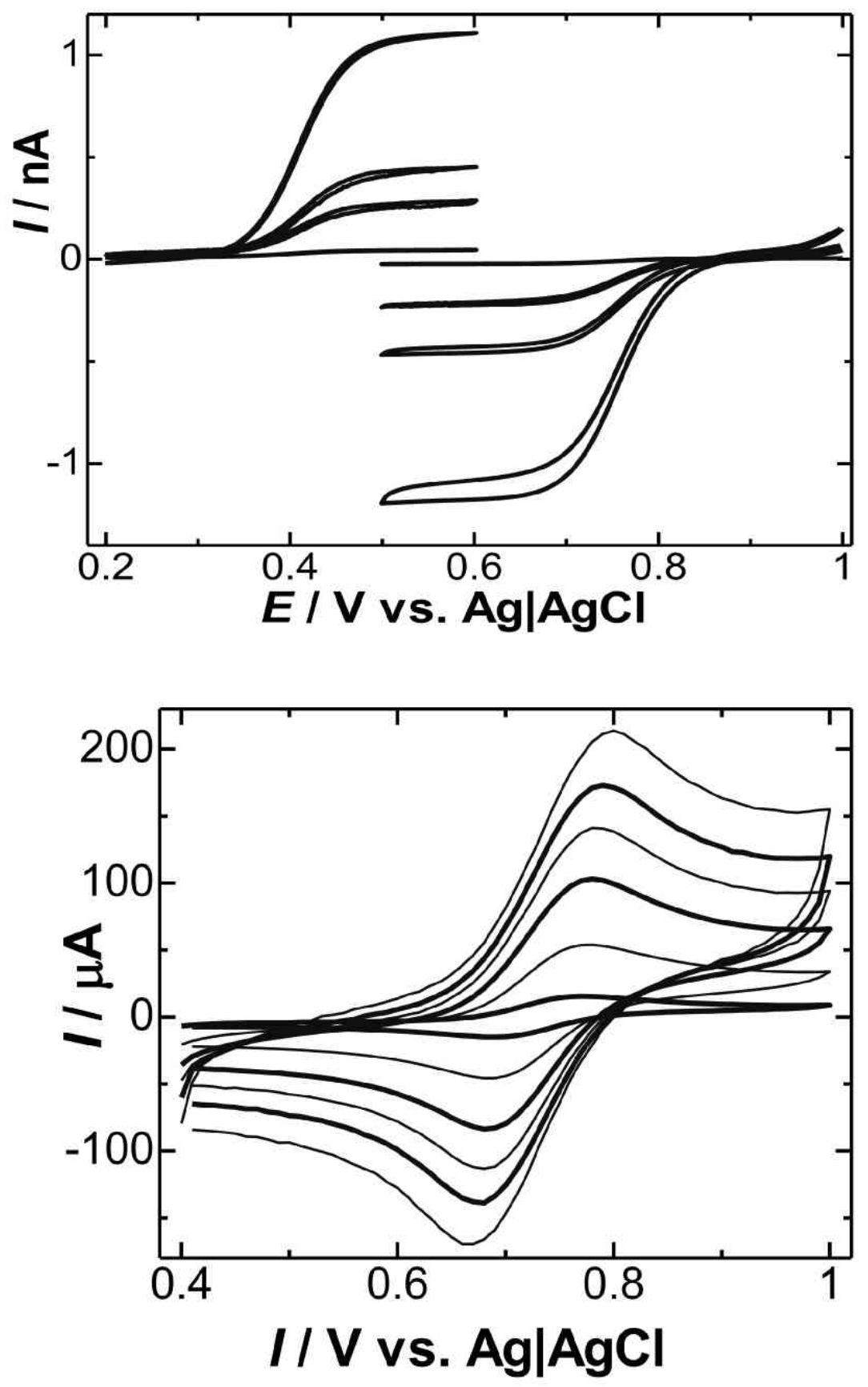

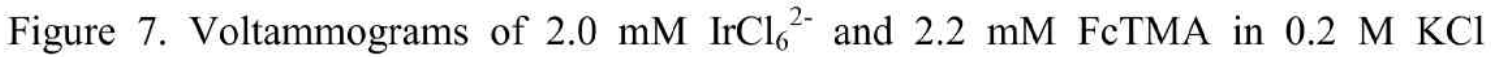
aqueous solution (A) at microelectrodes with $a=0.055,0.38,0.73$ and $1.9 \mu \mathrm{m}$, and (B) at the large electrode for $v=0.1,1,3,5,7$ and $10 \mathrm{~V} \mathrm{~s}^{-1}$ in different cells. 

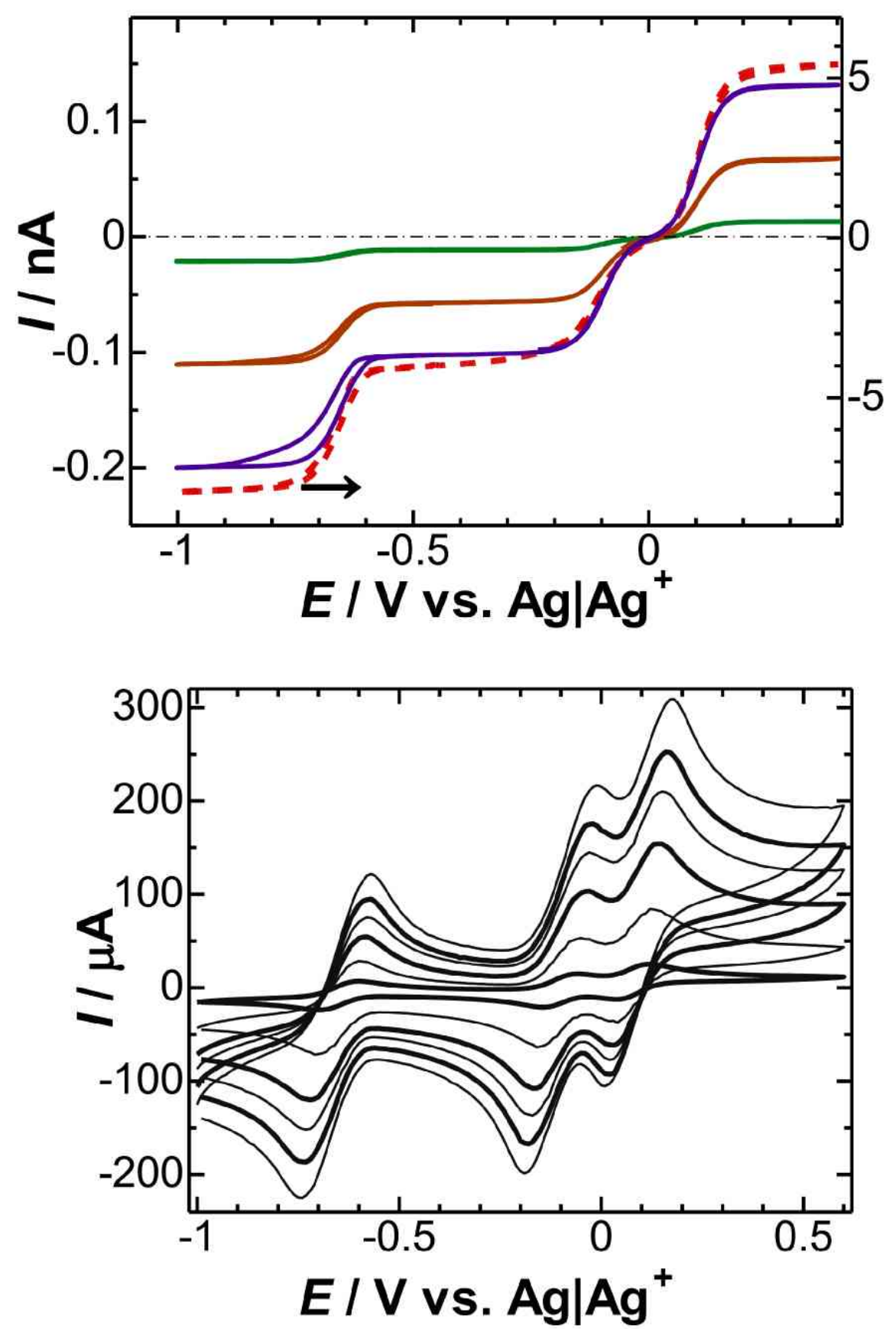

Figure 8. Voltammograms of $0.91 \mathrm{mM}$ TCNQ $+0.99 \mathrm{mM}$ ferrocene in $0.2 \mathrm{M} \mathrm{TBAPF}_{6}$ acetonitrile solution (A) at microelectrodes with $a=0.024,0.12,0.24$ and $8.9 \mu \mathrm{m}$ and (B) at the large electrode for $v=0.1,1,3,5,7$ and $10 \mathrm{~V} \mathrm{~s}^{-1}$. 

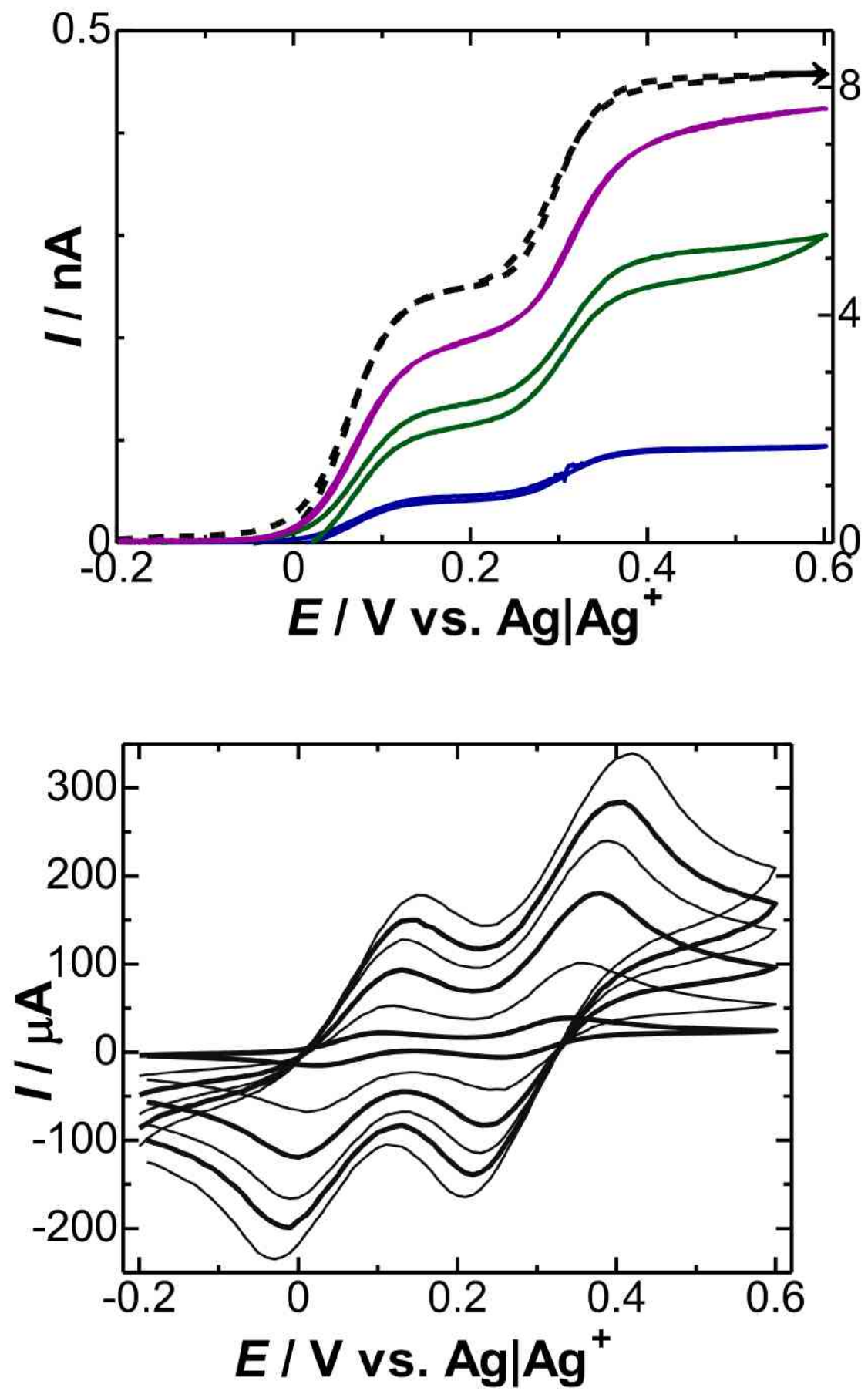

Figure 9. Voltammograms of $1.53 \mathrm{mM} \mathrm{FcA}+0.39 \mathrm{mM}$ ferrocene in $0.2 \mathrm{M} \mathrm{TBAPF}_{6}$ acetonitrile solution (A) at microelectrodes with $a=0.055,0.16,0.24$ and $6.0 \mu \mathrm{m}$ and (B) at the large electrode for $v=0.1,1,3,5,7$ and $10 \mathrm{~V} \mathrm{~s}^{-1}$. 


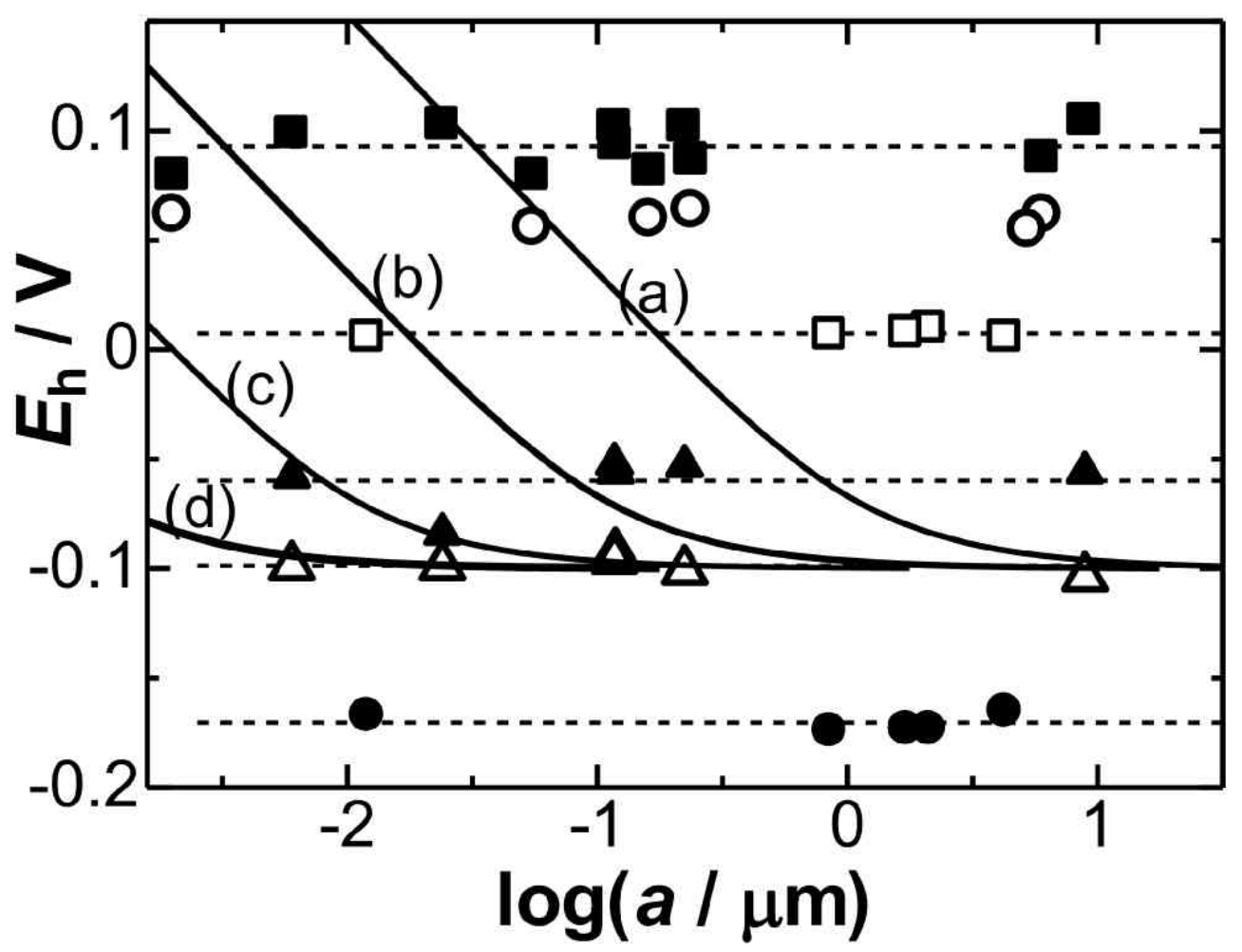

Figure 10. Dependence of halfwave potentials of (open squares) FcTMA with $-0.4 \mathrm{~V}$ gain in the plot, (filled circles) $\mathrm{Ru}\left(\mathrm{NH}_{3}\right)_{6}{ }^{3+}$, (open squares) $\mathrm{IrCl}_{6}{ }^{2-}$, (filled squares) ferrocene, (open triangles) first wave of TCNQ, (filled triangles) second wave of TCNQ with $0.6 \mathrm{~V}$ gain, and (open circles) $\mathrm{FcA}$ with -0.25 gain on the radii of electrodes. Curves were calculated from Eq. (10) at $\alpha=0.5, D=10^{-5} \mathrm{~cm}^{2} \mathrm{~s}^{-1}$ for $k^{\circ}=$ (a) 0.01 , (b) 0.1 , (c) 1.0 and (d) $10 \mathrm{~cm} \mathrm{~s}^{-1}$. 


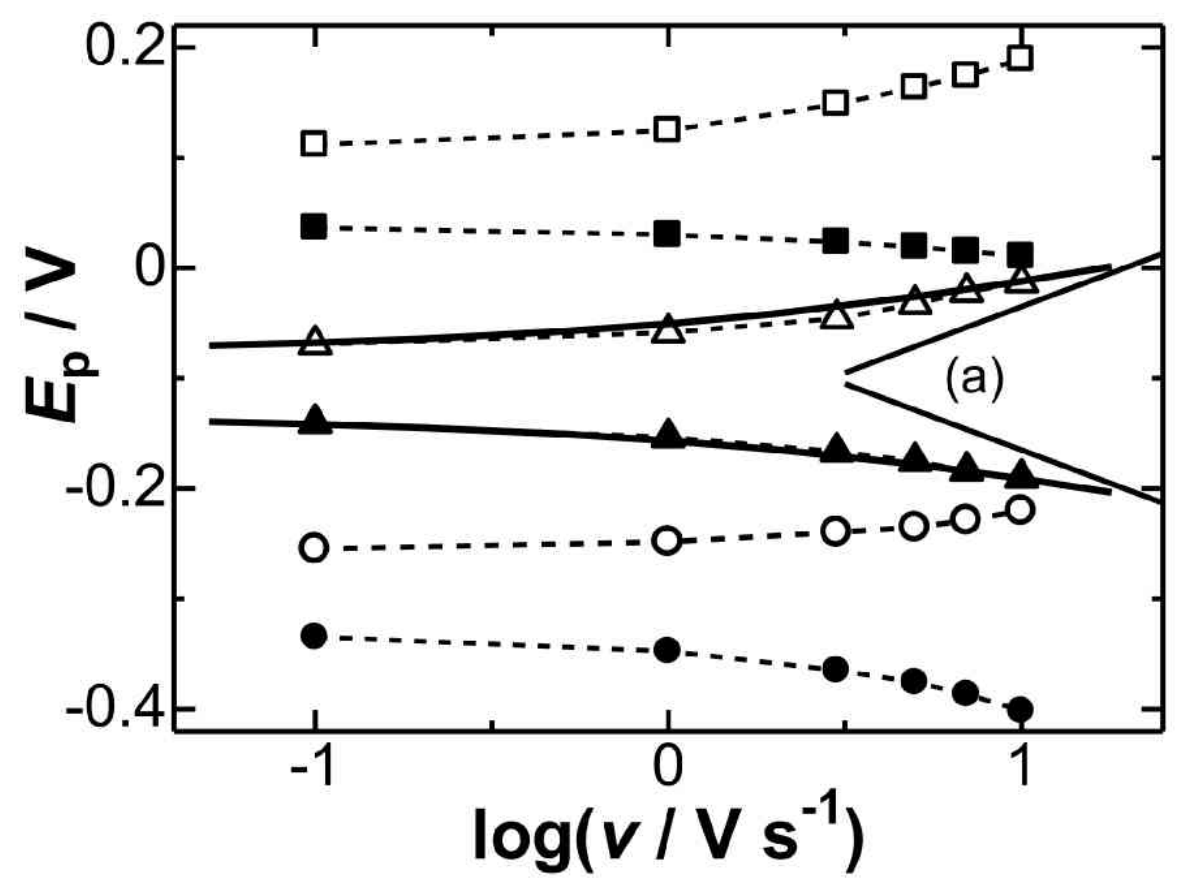

Figure 11. Scan rate dependence of the peak potentials of (squares) ferrocene, (triangles) the first wave of TCNQ, and (circles) the first wave of TCNQ with $0.35 \mathrm{~V}$ gain in the plot. The solid curves were computed by numerically solving the integral equation for $\alpha=0.5, D=10^{-5} \mathrm{~cm}^{2} \mathrm{~s}^{-1}$, and $k^{0}=0.017 \mathrm{~cm} \mathrm{~s}^{-1}$. Lines (a) have slopes of $\pm 0.12 \mathrm{~V}(= \pm 2.3 R T / 0.5 F)$. Dashed curves are connecting lines of points. 

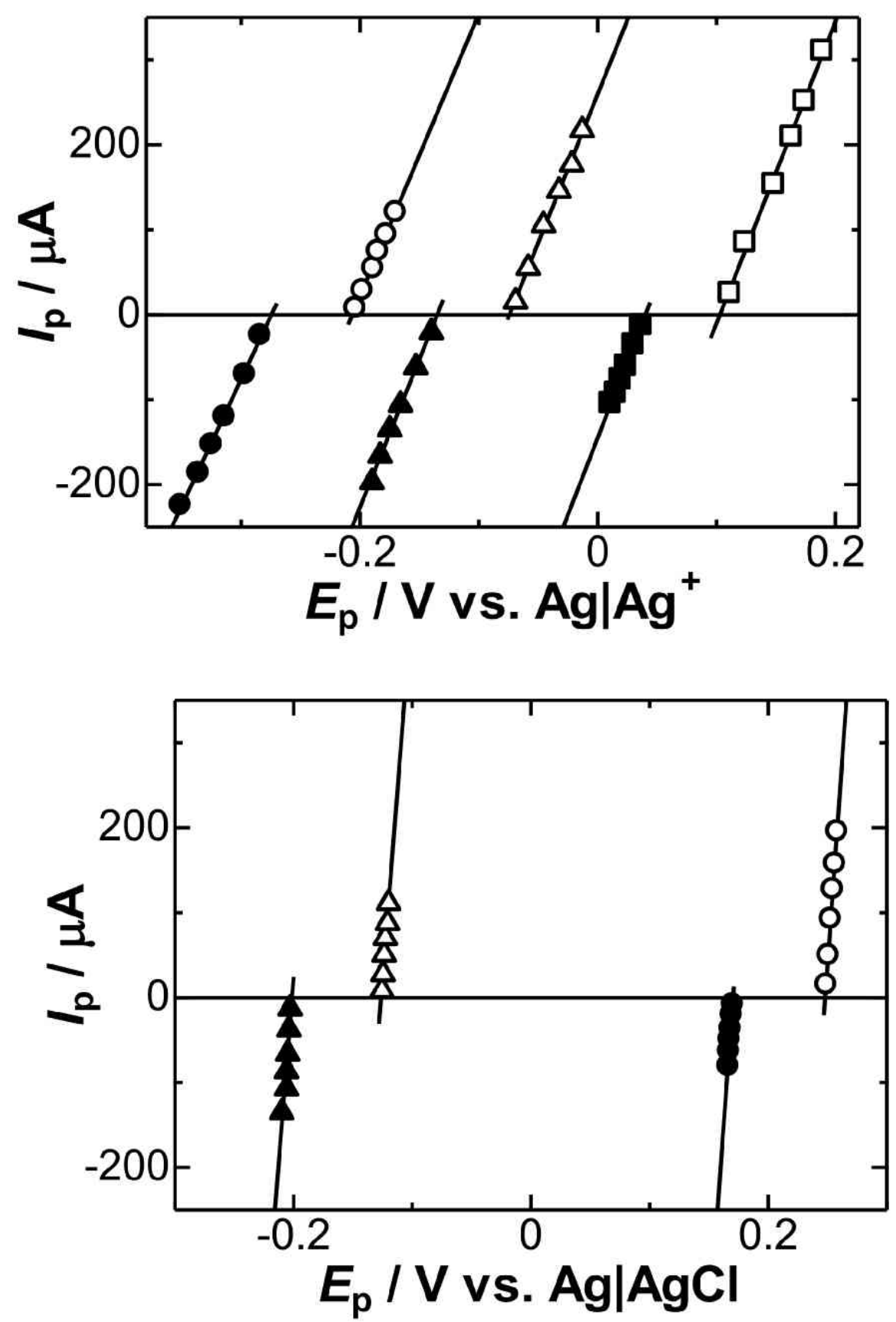

Figure 12. Plots of the peak currents against the peak potentials of (A) (circles) the first peaks of TCNQ, (triangles) the second peaks of TCNQ, (squares) ferrocene in $0.2 \mathrm{M}$ $\mathrm{TBAPF}_{6}$ acetonitrile solution and (B) (circles) FcTMA and (triangles) $\mathrm{Ru}\left(\mathrm{NH}_{3}\right)_{6}{ }^{3+}$ in 0.2 $\mathrm{M} \mathrm{KCl}$ aqueous solution, where values of $E_{\mathrm{p}}$ for TCNQ and FcTMA were shifted by 0.4 $\mathrm{V}$ and $-0.2 \mathrm{~V}$, respectively, for simplifying the representation. 


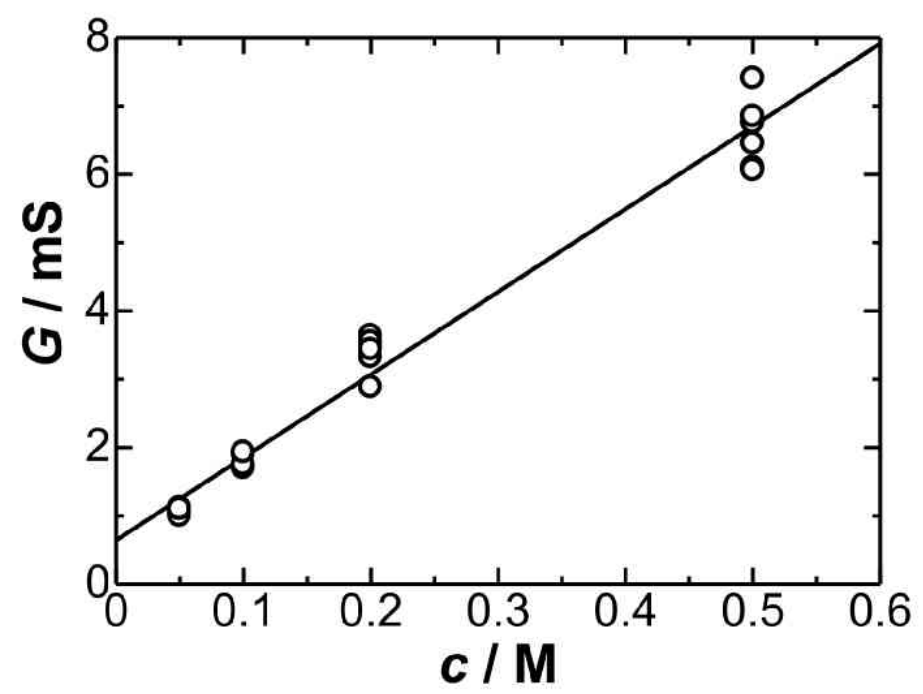

Figure 13. Plot of the conductance (slope of lines in Fig. 11(A)) for TCNQ, FcA and ferrocene against the concentrations of $\mathrm{TBAPF}_{6}$.

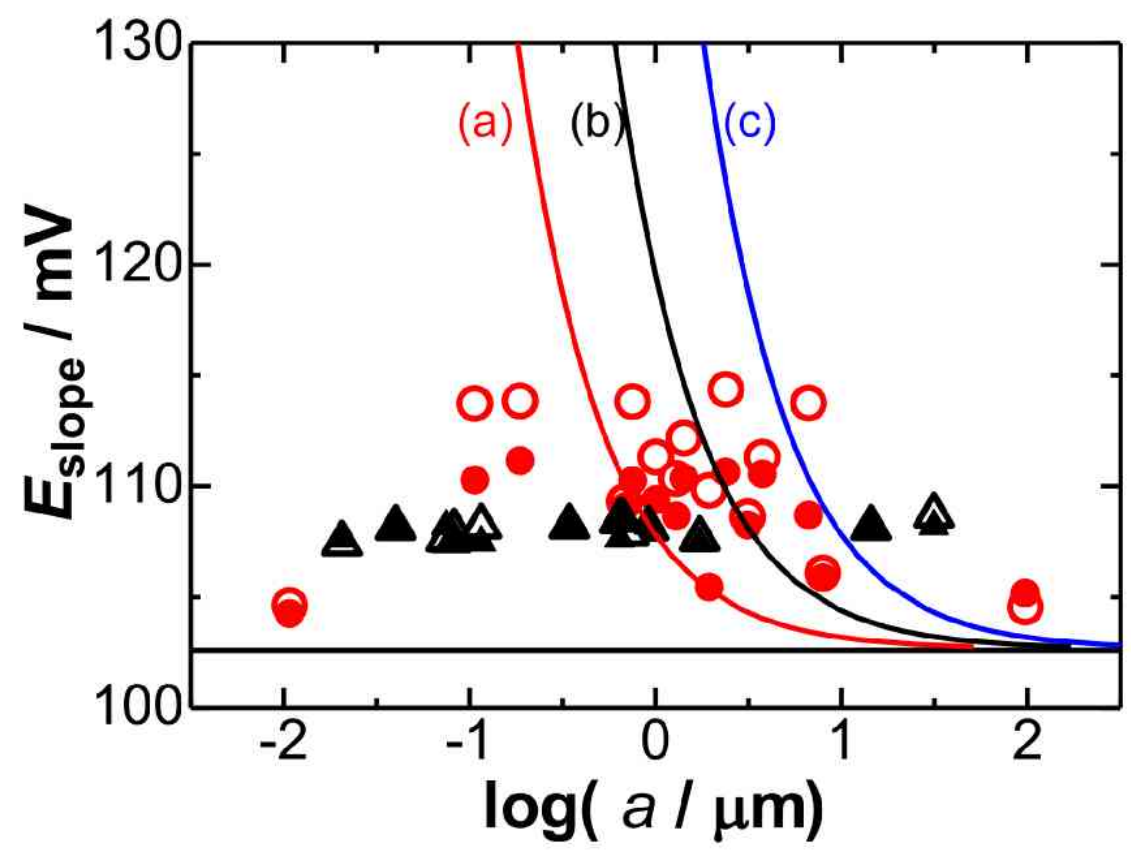

Figure 14. Variations of $E_{\text {slope }}$ with $\log (a)$ for (triangles) ferrocene and (circles) FcTMA, where filled and open marks are, respectively, for the forward and the backward scans. Curves are theoretical ones calculated from Eq. (8) for $k^{0}=$ (a) 1 , (b) 0.3 , and (c) $0.1 \mathrm{~cm}$ $\mathrm{s}^{-1}$ at $D=10^{-5} \mathrm{~cm}^{2} \mathrm{~s}^{-1}$. 


\section{References}

[1] K. Aoki, Electroanalysis 5 (1993) 627.

[2] C. Amatore, Electrochemistry at ultramicroelectrodes, in: I. Rubinstein (Ed.), Physical Electrochemistry: Principles, Methods and Applications, Marcel Dekker, New York, 1995, pp. 131-208.

[3] R.J.C. Brown, D.J.L. Brett, Microchim. Acta 164 (2009) 337

[4] D. J. Griffiths, Introduction to Electrodynamics, 2nd ed. Prentice Hall, New Jersey,1989, pp.1120-120.

[5] Y. Saito, Rev. Polarogr. Jpn. 15 (1968) 177.

[6] R. M. Penner, M. J. Heben, T. L. Longin, N. S. Lewis, Science 250 (1990) 1118.

[7] J. J. Watkins, J. Chen, H. S. White, H. D. Abruna, E. Maisonhaute, C. Amatore, Anal. Chem. 75 (2003) 3962.

[8] W.R. Fawcett, M. Opallo, Angew. Chem. 106 (1994) 2239.

[9] A.M. Bond, T.L.E. Henderson, D.R. Mann, T.F. Mann, W.Thormann, C.G. Zoski, Anal. Chem. 60 (1988) 1878.

[10] P. Sun, M.V. Mirkin, Anal. Chem. 78 (2006) 6526.

[11] A. S. Baranski, K. Winkler, W. R. Fawcett, J. Electroanal. Chem. 313 (1991) 367.

[12] D. O. Wipf, E. W. Kristensen, M. R. Deakin, R. M. Wightman, Anal. Chem. 60 (1988) 306.

[13] A. P. Abbott, C. L. Miaw, J. F. Rusling, J. Electroanal. Chem. 327 (1992) 31.

[14] G. Diao, Z. Zhang, J. Electroanal. Chem. 437 (1997) 17.

[15] R. Müller, L. Lamberts, M. Evers, J. Electroanal. Chem. 401 (1996) 183.

[16] D. Suwatchara, N.V. Rees, R.G. Compton, J. Electroanal. Chem. 669 (2012) 14.

[17] Z. J. Karpinski, R. A. Osteryoung, J. Electroanal. Chem. 349 (1993) 285.

[18] M. Rosvall, Electrochem. Commun. 2 (2000) 791.

[19] S.J. M. Rosvall, M. Sharp, A. Bond, J. Electroanal. Chem. 536 (2002) 161. 
[20] A.S. Baranski, P.M. Diakowski, J. Phys. Chem. B 110 (2006) 6776.

[21] A. D. Clegg, N. V. Rees, O. V. Klymenko, B. A. Coles, R. G. Compton, J.

Electroanal. Chem. 580 (2005) 78.

[22] M. V. Mirkin, T. C. Richards, A. J. Bard, J. Phys. Chem., 97 (1993) 7672.

[23] M. V. Mirkin, A. J. Bard, Anal. Chem. 84 (1992) 2293.

[24] N. Nioradze, J. Kim, S. Amemiya, Anal. Chem. 83 (2011) 828.

[25] S. Bollo, S. Finger, J.C. Sturm, L.J. Nunez-Vergara, J.A. Squella, Electrochim. Acta 52 (2007) 4892.

[26] H. Zhou, S. Dong, J. Electroanal. Chem. 425 (1997)55.

[27] H. Zhou, N. Gu, S. Dong, J. Electroanal. Chem. 441 (1998) 153.

[28] B.J. Feldman, A.G. Ewing, R. W. Murray, J. Electroanal. Chem. 194 (1985) 63.

[29] W.J. Bowyer, E.E. Engelman, D.H. Evans, J. Electroanal. Chem. 262 (1989) 67.

[30] L.K. Safford, M.J. Weaver, J. Electroanal. Chem. 312 (1991) 69.

[31] K. Aoki, Electrochem. Commun. 7 (2005) 523.

[32] K. Aoki, C. Zhang, J. Chen, T. Nishiumi, Electrochim. Acta 55 (2010) 7328.

[33] K. Aoki, H. Takeuchi, J. Chen, T. Nishiumi, Review of Polarography, 57 (2011) 101.

[34] R. Feeney, S. P. Kounaves, Electrochem. Commun. 1 (1999) 453.

[35] G. Diao, Z. Zhang, J. Electroanal. Chem. 410 (1996) 155.

[36] G. Diao, Z. Zhang, J. Electroanal. Chem. 414 (1996) 177.

[37] Y. Zhang, C.D. Baer, C. Camaioni-Neto, P. O’Brien, D.A. Sweigart, Inorg. Chem. 30 (1992) 1682.

[38] Y. Li, D. Bergman, B. Zhang, Anal. Chem. 81 (2009) 5496.

[39] H. Zhou, L. Ding, N. Gu, S. Dong, Electrochim. Acta 43 (1998) 3353.

[40] N. Gu, H. Zhou, L. Ding, Z. Shi, S. Dong, Solid State Ionics, 138 (2000) 123.

[41] Y. Zhang, J. Zhou, L. Lin, Z. Lin, Electroanalysis 20 (2008) 1490.

[42] C. G. Zoski, Electroanalysis 14 (2002) 1041. 
[43] R. M. Wightman, Science 311 (2006) 1570.

[44] J. Chen, K. Aoki, Electrochem. Commun. 4 (2002) 24.

[45] R. M. Penner, M. J. Heben, N. S. Lewis, Anal. Chem. 61 (1989) 1630.

[46] B. D. Pendley, H. D. Abruna, Anal. Chem. 62 (1990) 782.

[47] C. Lee, C. J. Miller, A. J. Bard, Anal. Chem. 63 (1991) 78.

[48] C. G. Zoski, B. Liu, A. J. Bard, Anal. Chem. 76 (2004) 3646.

[49] G. Wang, A. K. Bohaty, I. Zharov, H. S. White, J. Am. Chem. Soc. 128 (2006) 13553.

[50] B. Zhang, J. Galusha, P. G. Shiozawa, G. Wang, A. J. Bergren, R. M. Jones, R. J.

White, E. N. Ervin, C. C. Cauley, H. S. White, Anal. Chem. 79 (2007) 4778.

[51] K. Aoki, J. Chen, H. Zhang, J. Electroanal. Chem. 610 (2007) 211.

[52] K. Aoki, K. Tokuda, H. Matsuda, J. Electroanal. Chem. 235 (1987) 87.

[53] H. Matsuda, Y. Ayabe, Z. Elektrochem. 59 (1955) 494.

[54] K. Aoki, C. Ouyang, J. Chen, T. Nishiumi, J. Solid State Electrochem. 15 (2011) 2305 .

[55] K. Aoki, O. Chun, C. Zhang, J. Chen, T. Nishiumi, Int. J. Electrochem. Sci., 7 (2012) 5880 .

[56] K. Aoki, Y. Guo, J. Chen, J. Electroanal. Chem, 629 (2009) 73.

[57] Y. Guo, K. Aoki, J. Chen, T. Nishiumi, Electrochim. Acta, 56 (2011) 3727.

[58] K. Aoki, Y. Hou, J. Chen, T. Nishiumi, J. Electroanal. Chem. J. Electroanal. Chem. $689(2013) 124$. 